\title{
GOAL PRIMING AND SELF-EFFICACY: INDEPENDENT CONTRIBUTIONS TO MOTOR PERFORMANCE
}

\author{
JEAN-BAPTISTE LÉGAL AND THIERRY MEYER
}

\author{
Université Paris Ouest
}

There is a long tradition in research concerning the way goals are set and pursued (for reviews, see Austin \& Vancouver, 1996; Gollwitzer \& Moskowitz, 1996). Researchers have broadly explored influences of the goal's content and characteristics on performance (e.g., Locke \& Latham, 1990; Elliot \& Harackiewicz, 1994). Motivation, volition, and self-regulation processes also affect goal-directed behavior (e.g., Bandura, 1986; Gollwitzer, 1990; Bandura \& Locke, 2003). Specifically, self-efficacy, i.e., personal beliefs about its own abilities and efficacy (Bandura, 1997), is a powerful predictor of performance. Another line of research provided evidences about nonconscious goal pursuit (e.g., Chartrand \& Bargh, 1996). Goals unobtrusively activated in memory can trigger a nonconscious goal-pursuit process which leads to outcomes similar to those of conscious goal pursuit. In this study, how selfefficacy and goal priming, i.e., nonconscious activation of goal-related concepts, contribute to performance of a motor task guided by an assigned goal was explored.

Research concerning deliberate goal setting and pursuit show that, given its characteristics, a goal can lead to more or less effort and commitment, and consequently, to different levels of performance (e.g., Locke \& Latham, 1990, 2004). For instance, it is well-established that specific goals lead to better performance than vague (or "do your best") goals, or that difficult goals, 
compared with easier ones, lead to greater effort and commitment, which in turn result in better performance.

With the framework of conscious goal pursuit, another important regulator is self-efficacy, or one's beliefs about personal skills and efficacy (Schwarzer, 1992). For Bandura (1994), self-efficacy is a key factor concerning goal setting and goal selection, as well as for effort and persistence on task, influencing the goal-pursuit process from goal selection to attainment, including self-regulation of behavior. In the framework of their work-motivation model, Locke and Latham (2004) hypothesized that self-efficacy moderates goal difficulty and affects performance through effects on direction, effort, persistence, and task strategies. Specifically, in comparison with people with low self-efficacy, people with high self-efficacy are more committed to assigned goals, find and use better strategies to attain goals, and respond more positively to negative feedback (Locke \& Latham, 1990, 2002; Bandura \& Locke, 2003). Goal Setting Theory (e.g., Locke \& Latham, 1990) and Social Cognitive Theory (e.g., Bandura, 1994) are rooted in an agentic perspective, focusing on intentional and deliberate processes. In that perspective, people not only plan actions but also consciously motivate their efforts anticipatorily.

In most models, goal pursuit is considered a voluntary and consciously controlled activity, although goal pursuit can also occur outside of awareness, intent, and control (Bargh, 1990; Bargh \& Chartrand, 1999; Bargh, Gollwitzer, Lee-Chai, Barndollar, \& Trötschel, 2001; Chartrand \& Bargh, 2002; Shah \& Kruglanski, 2002; Shah, 2003). According to this view, goals can be triggered volitionally but also automatically. It is well demonstrated that knowledge structures such as schemas, stereotypes, or traits are stored in memory and can be activated automatically and influence behavior and judgment (for a review, see Bargh \& Chartrand, 1999). Goals, as knowledge structures, also can automatically activate. Once activated, either consciously or nonconsciously, a goal operates and guides behavior until goal completion. Nonconscious goal activation is generally manipulated through the activation of goal-related words or concepts. Thus, for instance, priming words such as "succeed, win, compete" may activate the goal of good performance (Bargh, et al., 2001). Interestingly, it has been demonstrated that nonconsciously activated goals and consciously pursued goals led to comparable outcomes. For instance, nonconsciously activated goals of memorization or impression formation produced the same effects as explicit instructions (Chartrand \& Bargh, 1996). Moreover, Bargh, et al. (2001) demonstrated that nonconscious and conscious goals share the same main characteristics: persistence facing obstacles, resumption after interruption, and increase in intensity up to completion.

A growing number of studies demonstrated that nonconscious goals 
influence a broad range of behaviors: judgment and interpersonal relationships (Fitzsimons \& Bargh, 2003), anagram resolution or production (Shah \& Kruglanski, 2002), recall and recognition performance (Chartrand \& Bargh, 1996; Mitchell, Macrae, Schooler, Rowe, \& Milne, 2002), and voice intensity (Aarts \& Dijksterhuis, 2003). As in the case of stereotype priming (e.g., Dijksterhuis \& van Knippenberg, 1998; Dijksterhuis, 2004; Follenfant, Légal, Dit-Dinard, \& Meyer, 2005), goal priming can increase or decrease performances as a function of its content (Légal, Meyer, \& Delouvée, 2007).

If goal-priming effects on behavior are clearly demonstrated, much remains to be discovered concerning the way nonconscious and conscious goals are related (Bargh, 2006). Particularly, the question of joint conscious and nonconscious regulations of behavior remains unresolved. Another important and unresolved issue concerns competition between nonconscious and conscious goals. How do conscious and nonconscious goal influences combine? Is there a selection process making one of these "win"? Are nonconscious effects eliminated or do they continue to affect behavior? Does priming compatible with one's current conscious goal improve performance? Inversely, does goal-incompatible priming lead to a decrease in performance?

Nonconscious goal priming (e.g., Bargh, et al., 2001) and conscious goal pursuit (e.g., Locke \& Latham, 1990, 2002) were explored. Particularly, the question of the joint effect of goal priming and self-efficacy was addressed. If the relation between conscious goal and self-efficacy is largely discussed (e.g., Locke \& Latham, 2004), the relation between nonconscious goal and self-efficacy remains unexplored. Given that self-regulation is a conscious process, the effects of goal priming and self-efficacy could be independent. Inversely, processes triggered by the priming manipulation, as they are nonconscious, could be unaffected by self-efficacy, supposedly a conscious and self-reflective process. So, one may expect a main effect of goal-related priming as well as a main effect of self-efficacy on performance. Also explored was the idea of compatibility between the nonconsciously primed content and task instruction (i.e., conscious goal). Specifically, priming manipulation involved a content that was compatible or not in regard with the conscious goal's instructions.

In the study, participants performed a drawing task in which they had to pursue a conscious accuracy goal assigned through written instructions. Before they performed the task, they were primed with accuracy-related words (compatible condition), inaccuracy-related words (incompatible condition), or received no priming (control condition). In the case of compatibility between primed content and consciously held goals, performance was expected to be optimal. Conversely, when primed content and conscious goals were not compatible, performance should be lower. So, compared with a no priming condition, performance should be better in the case of compatibility 
between primed content and conscious goal and worse if these are incompatible. According to the literature about self-efficacy and conscious goal pursuit, better performance of the task was also expected in people with high rather than low self-efficacy. Finally, the best performance should be obtained by participants primed with accuracy-related words and having high self-efficacy. Conversely, the worst performance should be observed in the case of inaccuracy-related priming and of low self-efficacy.

\section{MethoD}

\section{Participants and Design}

Sixty-seven right-handed undergraduate female students of the University of Reims participated in the experiment. They received no course credit or monetary reward for participation. Following a median-split procedure, participants were distributed in the conditions as a function of score (high vs low) on the drawing Self-efficacy scale $\left(M d n=29 ; M_{\text {High }}=31.73, S D_{\text {High }}=\right.$ 2.77 and $M_{\text {Low }}=24.90, S D_{\text {Low }}=2.70$ ). The design was a 3 (priming: inaccuracy, no prime, accuracy) by 2 (self-efficacy: low vs high) between-subjects design.

\section{Materials and Measures}

Priming.-The priming procedure took the form of a Scrambled Sentence Task (e.g., Srull \& Wyer, 1979; Bargh \& Chartrand, 2000). Participants were requested to produce sentences using words presented in a scrambled order. Two versions of this task were constructed. In the first one, primes were related to accuracy (goal-compatible priming); in the second one, primes were related to inaccuracy (goal-incompatible priming). In the priming conditions, 20 of the 30 sentences contained a word or an expression related to accuracy (e.g., sharpshooter, detailed, thoroughness) or inaccuracy (e.g., clumsy, inaccurately, approximate). The 10 remaining sentences contained neutral words (e.g., book, soup, pen) and were used in both versions. In the no priming condition, participants were not given the Scrambled Sentence Task.

Motor task: the Slalom Game.-A drawing task, the "Slalom Game," was designed and administered to participants. This discrete task requires attention, coordination, visuospatial abilities, and precise hand control. Participants received an $\mathrm{A} 4$ sheet on which was printed a circle (diameter $=10$ $\mathrm{cm}$ ) composed of a dotted line (the space between each of the 72 dots was 2 $\mathrm{mm}$ ). The instruction was to draw a continuous line from point A (start) to point B (finish) by "slaloming" between the dots. The task (size of the circle and space between the dots) had been pretested to provide a real challenge in terms of difficulty. The main dependent measure was the number of times the drawn line touched the dotted line. 
Self-efficacy scale.-A modified version of the General Self-efficacy scale (Schwarzer \& Jerusalem, 1995) was administered. Each of the 10 original items was modified to apply to a specific domain of production of accurate movements. For each item (e.g., "I can always be accurate in my moves if I try hard enough"), participants had to indicate their choice using a Likerttype scale (anchored by 1: False and 4: True). The internal consistency of the scale was good (Cronbach alpha $=.81$ ).

\section{Procedure}

Participants were informed that they would be taking part in several unrelated tasks: a short survey (the Self-efficacy scale), a language test (the Scrambled Sentence Task), and a motor skill test (the Slalom Game). Assignment to the priming condition (i.e, inaccuracy, no prime, or accuracy) was random. In the no prime condition, participants only filled in the Self-efficacy scale and performed the motor task. For the Slalom Game, all participants received an accuracy goal. Instructions read, "On this sheet you can see a circular dotted line. With your pen, you have to draw a continuous line by slaloming between the dots, beginning at point $\mathrm{A}$ and finishing at point B. You have to draw the line without touching the dots. Perform this task as accurately as possible." There was no time pressure, and participants were instructed to perform the Slalom Game at their own pace. After the task, participants answered manipulations check items. Finally, they were debriefed and thanked.

\section{RESULTS}

\section{Manipulations Check}

Priming and conscious goal.-Suspicions regarding the relationship between the priming manipulation and the motor task were probed using a questionnaire with questions concerning what the participants thought the experiment was about and whether they thought one part or task in the experiment might have affected another part or task ("funneled" questionnaire, see Bargh \& Chartrand, 2000). No participant indicated any awareness or suspicion that the words used on the priming task were related to the subsequent task. To ensure participants had pursued the conscious accuracy goal, they were asked to recall the instructions they read before performing the motor task. Analysis of recalls indicated that instructions had been well understood as an accuracy goal.

Priming and self-efficacy.-As the measure of self-efficacy took place after the priming manipulation, whether priming had an effect on self-efficacy score of participants was checked. The one-way analysis of variance indicated no effect of priming on self-efficacy beliefs $(F<1.00)$. Mean scores of self-efficacy were not different for participants primed with inaccuracy-re- 
lated words $(M=29.9)$, accuracy-related words $(M=28.4)$, and for participants who received no priming $(M=27.4)$.

\section{Performance}

The mean number of errors (i.e., the number of times the drawn line touched the dotted line) was entered into a 3 (priming: inaccuracy, no prime, accuracy) $\times 2$ (self-efficacy: low vs high) between-subjects analysis of variance. The analysis yielded a main effect of priming on performance $\left(F_{1,61}=\right.$ $\left.5.96, p<.02, \eta^{2}=.10\right)$. Compared with the No prime condition, the Accuracy-primed group committed less errors (i.e., performed the task more accurately) than the Inaccuracy-primed group. The main effect of self-efficacy was also significant $\left(F_{1,61}=6.38, p<.02, \eta^{2}=.11\right)$. As expected, participants with high self-efficacy performed better than participants with low self-efficacy. Interaction of the factors was not significant $(F<1.00)$.

Planned comparisons yielded a significant difference between the high self-efficacy with accuracy-priming conditions and the low self-efficacy with inaccuracy-priming conditions $\left(F_{1,61}=10.51, p<.02\right)$. Differences in performance between these groups and the Control group were not significant (respectively, $F_{1,61}=2.94$, ns and $F_{1,61}=2.99$, ns).

\section{TABLE 1}

Mean Number of Times Drawn Line Touched Dotted Line as Function of Priming and Self-efficacy

\begin{tabular}{lcccccc}
\multirow{2}{*}{ Priming Group } & $n$ & \multicolumn{2}{c}{ Low Self-efficacy } & & \multicolumn{2}{c}{ High Self-efficacy } \\
\cline { 3 - 4 } \cline { 6 - 7 } & $M$ & & $S D$ & & $M$ & $S D$ \\
\hline Accuracy & 7.7 & 4.89 & & 3.7 & 3.97 \\
No Prime (control) & 8.9 & 2.58 & & 5.6 & 1.49 \\
Inaccuracy & 11.3 & 8.00 & & 7.6 & 5.48 \\
\hline
\end{tabular}

\section{Discussion}

This study provides evidence concerning the joint influence of goal priming and self-efficacy on performance. It also provides elements about the effects of compatibility and incompatibility between a nonconsciously primed content and a consciously pursued goal on performance. Both the nonconscious primes and the conscious goal used were related to performance. Goal-compatible primes tended to improve performance, whereas with goal-incompatible primes, performance tended to deteriorate.

Two explanations could account for the observed effect of priming on performance. First, in reference to literature concerning nonconscious motivation (e.g., Chartrand \& Bargh, 2002), it is possible that goal-related primes influence the allocation of available motivational resources, promoting a focus of the resources on a single goal in the case of compatibility between primed content and conscious goal and, inversely, a spreading of resources 
in the case of goal-incompatible primes. Another plausible explanation is that goal-related primes influence the allocation of attentional resources. So, when conscious goal and primed words are compatible, priming would promote an attentional focus, whereas incompatibility between conscious goal and primed content would lead to divided attention. Concerning self-efficacy, results were in line with classical findings, indicating that people with high self-efficacy perform better than people with low self-efficacy (e.g., Bandura, 1997).

An additive effect of conscious and nonconscious self-regulation on performance was observed. Self-efficacy and priming independently influenced performance, although the two variables did not interact. If conscious and nonconscious goal pursuits share the same characteristics and presumably rely on the same core mechanisms (Bargh, et al., 2001; Chartrand \& Bargh, 2002), self-regulatory processes such as ones associated with self-efficacy appear to be exclusive features of consciously pursued goals. Thus, results suggested that goal-related priming and conscious goal pursuit may rely on complementary rather than on incompatible processes and open interesting research perspectives. On the one hand, nonconscious regulation of behavior relies on automatic processes which are rapid, have a low cost in mental resources, and operate in parallel (Meier, Morger, \& Graf, 2003). On the other hand, conscious self-regulation of behaviors and goals that rely on limited resources and costs are by far higher (Muraven \& Baumeister, 2000). So, compared with conscious self-regulation, nonconscious regulation of behavior certainly saves resources that could be used in the performance of a conscious task. Nonconscious regulation of behavior through a priming manipulation could be a way to improve (or hinder, as a function of the primed content's characteristics) people's efficacy in the performance of a variety of tasks. Particularly, priming procedures could be used as a complement to instructions. Such procedures may help people to focus on their activity and, for instance, improve testimony through a better recognition or allow a better target detection. One can also imagine that specific priming procedure could be used as a treatment of depression through modifying self-talk. Depressed people tend to focus on negative thought and negative self-talk, which has been proposed to limit resources for psychological changes. Goal priming could be a way to improve the use of mental resources as well as promote positive self-talk.

Results are also in line with the idea that nonconscious processes play an important role in everyday life, even in tasks requiring attention and cognitive resources. This is the case, for instance, when important decisions have to be made (e.g., choose an apartment or a roommate; Dijksterhuis, 2004). It also appears to be true for tasks requiring high attention, such as complex motor tasks (Légal, Meyer, \& Delouvée, 2007). So, given its charac- 
teristics and particularly its low cost in resources, nonconscious regulation of behavior could constitute a very adaptive way to regulate performance in a broad range of activities.

Researchers must consider the problem in greater detail. For instance, in this study, the conscious goal was a difficult "do your best" goal (one of low specificity). Locke and Latham (1990) stated in their Goal Setting Theory that this type of goal is not optimal for highest performance and work motivation, a difficult but specific goal is the best way to focus and improve goal pursuit and performance. It would also be fruitful to investigate the way in which feedback and goal specificity are influenced by the presence of nonconscious motives. Priming incompatible goal-related content could also be considered as a performance-avoidance goal (Elliot \& Harackiewicz, 1994; Bell \& Kozlowsli, 2002), so aspects of goal-orientation models should be explored to test the underlying processes more directly.

Finally, nonconscious goal pursuit and affect-related issues also provide interesting perspectives. It has been demonstrated that positive affect, when associated to a goal, facilitates its pursuit (Custers \& Aarts, 2005), but other questions remain. For instance, does goal priming modify or create affects? Does conflict between conscious and nonconscious goals create a specific affective state, such as a kind of cognitive dissonance? If such a state exists, what are its consequences on behavior and cognitive processes?

\section{REFERENCES}

Aarts, H., \& Dijksterhuis, A. (2003) The silence of the library: environmental control over social behavior. Journal of Personality and Social Psychology, 84, 18-28.

Austin, J. T., \& Vancouver, J. B. (1996) Goal construct in psychology: structure, process and content. Psychological Bulletin, 120, 338-375.

Bandura, A. (1986) Social foundations of thought and action: a social cognitive theory. Englewood Cliffs, NJ: Prentice-Hall.

Bandura, A. (1994) Self-efficacy. In V. S. Ramachaudran (Ed.), Encyclopedia of human behavior. New York: Academic Press. Pp. 71-81.

Bandura, A. (1997) Self-efficacy: the exercise of control. New York: Freeman.

Bandura, A., \& Locke, E. (2003) Negative self-efficacy and goal effects revisited. Journal of Applied Psychology, 88, 87-99.

BARGH, J. A. (1990) Auto-motives: preconscious determinants of social interaction. In E. T. Higgins \& R. M. Sorrentino (Eds.), Handbook of motivation and cognition: foundations of social behavior. Vol. 2. New York: Guilford. Pp. 93-130.

BARGH, J. A. (2006) What have we been priming all these years? On the development, mechanisms, and ecology of nonconscious social behavior. European Journal of Experimental Social Psychology, 36, 147-168.

Bargh, J. A., \& Chartrand, T. L. (1999) The unbearable automaticity of being. American Psychologist, 54, 462-479.

Bargh, J. A., \& Chartrand, T. L. (2000) The mind in the middle: a practical guide to priming and automaticity research. In H. Reis \& C. Judd (Eds.), Handbook of research methods in social psychology. New York: Cambridge Univer. Press. Pp. 253-285.

Bargh, J. A., Gollwitzer, P. M., Lee-Chai, A., Barndollar, K., \& Trötschel, R. (2001) The automated will: nonconscious activation and pursuit of behavioral goals. Journal of Personality and Social Psychology, 81, 1014-1027.

Bell, B. S., \& Kozlowski, S. W. J. (2002) Goal orientation and ability: interactive effects on self-efficacy, performance and knowledge. Journal of Applied Psychology, 87, 497-505. 
Chartrand, T. L., \& Bargh, J. A. (1996) Automatic activation of impression formation and memorization goals: nonconscious goal priming reproduces effects of explicit task instructions. Journal of Personality and Social Psychology, 71, 464-478.

Chartrand, T. L., \& Bargh, J. A. (2002) Nonconscious motivations: their activation, operation, and consequences. In A. Tesser, D. Stapel, \& J. Wood (Eds.), Self and motivation: emerging psychological perspectives. Washington, DC: American Psychological Association. Pp. 13-41.

Custers, R., \& Aarts, H. (2005) Positive affect as implicit motivator: on the nonconscious operation of behavioral goals. Journal of Personality and Social Psychology, 89, 129-142.

Dijksterhuis, A. (2004) Think different: the role of unconscious and conscious processes in attitude formation and decision-making. Journal of Personality and Social Psychology, 87, 586-598.

Dijksterhuis, A., \& van Knippenberg, A. (1998) The relation between perception and behavior or how to win a game of Trivial Pursuit. Journal of Personality and Social Psychology, 74, 865-877.

Elliot, A. J., \& Harackiewicz, J. M. (1994) Goal setting, achievement orientation and intrinsic motivation: a mediational analysis. Journal of Personality and Social Psychology, 54, 5-12.

Fitzsimons, G. M., \& Bargh, J. A. (2003) Thinking of you: nonconscious pursuit of interpersonal goals associated with relationship partners. Journal of Personality and Social Psychology, 84, 148-163.

Follenfant, A., Légal, J-B., Dit-Dinard, M., \& Meyer, T. (2005) Effect of stereotypes activation on behavior: an application in a sport setting. Revue Européenne de Psychologie Appliquée, 55, 121-129.

Gollwitzer, P. M. (1990) Action phases and mind-sets. In E. T. Higgins \& R. M. Sorrentino (Eds.), Handbook of motivation and cognition. New York: Guilford. Pp. 53-92.

Gollwitzer, P. M., \& Moskowitz, G. B. (1996) Goal effects on action and cognition. In E. T. Higgins \& A. W. Kruglanski (Eds.), Social psychology: bandbook of basic principles. New York: Guilford. Pp. 361-399.

Légal, J-B., Meyer, T., \& Delouvée, S. (2007) Effect of compatibility between conscious goal and nonconscious priming on performance. Current Research in Social Psychology, 12, 8090.

Locke, E. A., \& Latham, G. P. (1990) A theory of goal setting and task performance. Englewood Cliffs, NJ: Prentice-Hall.

Locke, E. A., \& Latham, G. P. (2002) Building a practically useful theory of goal setting and task motivation: a 35-year odyssey. American Psychologist, 57, 705-717.

Locke, E. A., \& Latham, G. P. (2004) What should we do about motivation theory? Six recommendations for the twenty-first century. Academy of Management Review, 29, 388-403.

Meier, B., Morger, V., \& Graf, P. (2003) Competition between automatic and controlled processes. Consciousness and Cognition, 12, 309-319.

Mitchell, J. P., Macrae, C. N., Schooler, J., Rowe, A. C., \& Milne, A. B. (2002) Directed remembering: subliminal cues alter nonconscious memory strategies. Memory, 10, 381-388.

Muraven, M., \& Baumeister, R. F. (2000) Self-regulation and depletion of limited resources: does self-control resemble a muscle. Psychological Bulletin, 126, 247-259.

Schwarzer, R. (Ed.) (1992) Self-efficacy: thought control of action. Washington, DC: Hemisphere.

Schwarzer, R., \& Jerusalem, M. (1995) Generalized Self-Efficacy scale. In J. Weinman, S. Wright, \& M. Johnston (Eds.), Measures in health psychology: a user's portfolio. Windsor, UK: Nfer-Nelson. Pp. 35-37.

SHAH, J. Y. (2003) Automatic for the people: how representation of significant others implicitly affects goal pursuit. Journal of Personality and Social Psychology, 84, 661-681.

Shah, J. Y., \& Kruglanski, A. W. (2002) Priming against your will: how accessible alternatives affect goal pursuit. Journal of Experimental Social Psychology, 38, 368-383.

SRULL, T. K., \& Wyer, R. S., JR. (1979) The role of category accessibility in the interpretation of information about persons: some determinants and implications. Journal of Personality and Social Psychology, 37, 1660-1672. 